\title{
Retail optimization in Romanian metallurgical industry by applying of fuzzy networks concept
}

\author{
Adrian Ioana*, Augustin Semenescu, Mihnea Costoiu, and Dragos Marcu \\ University Politehnica of Bucharest, Spl. Independentei 313, Bucharest, Romania
}

\begin{abstract}
Our article presents possibilities of applying the concept Fuzzy Networks for an efficient metallurgical industry in Romania. We also present and analyze Fuzzy Networks complementary concepts, such as Expert Systems (ES), Enterprise Resource Planning (ERP), Analytics and Intelligent Strategies (SAI). The main results of our article are based on a case study of the possibilities of applying these concepts in metallurgy through Fuzzy Networks. Also, it is presented a case study on the application of the FUZZY concept on the Romanian metallurgical industry.
\end{abstract}

\section{Introduction}

The Romanian metallurgical industry suffered unfortunately an important and severe regression during last period. So, many production works of this industry branch have been closed or severely diminished production. Most relevant examples in this regard are the Steel works of Călan, Oţelul Roşu, Reşita, Târgovişte [1-2].

An expert system is made of five components: Knowledge Base (KB), Inference Engine (IE), Dialogue Interface (DI), Knowledge Acquiring Module (KAM), Explanatory Module (EM) [3-7].

The explanations in such a system, if designed accordingly, improve the way the users perceive and accept the system.

Figure 1 shows the most important modules that make up a rule-based expert system. The user interacts with the system through a user interface which may use menus, natural language or any other style of interaction).

Then an inference engine is used to reason with both the expert knowledge (extracted from our friendly expert) and data specific to the particular problem being solved. The expert knowledge will typically be in the form of a set of IF-THEN rules.

The case specific data includes both data provided by the user and partial conclusions (along with certainty measures) based on this data. In a simple forward chaining rule-based system the case specific data will be the elements in working memory.

Almost all expert systems also have an explanation subsystem, which allows the program to explain its reasoning to the user.

Some systems also have a knowledge base editor which help the expert or knowledge engineer to easily update and check the knowledge base.

\footnotetext{
* Corresponding author: adyioana@gmail.com
} 
One important feature of expert systems is the way they (usually) separate domain specific knowledge from more general purpose reasoning and representation techniques. The general purpose bit (in the dotted box in the figure) is referred to as an expert system shell.

Expert System Shell

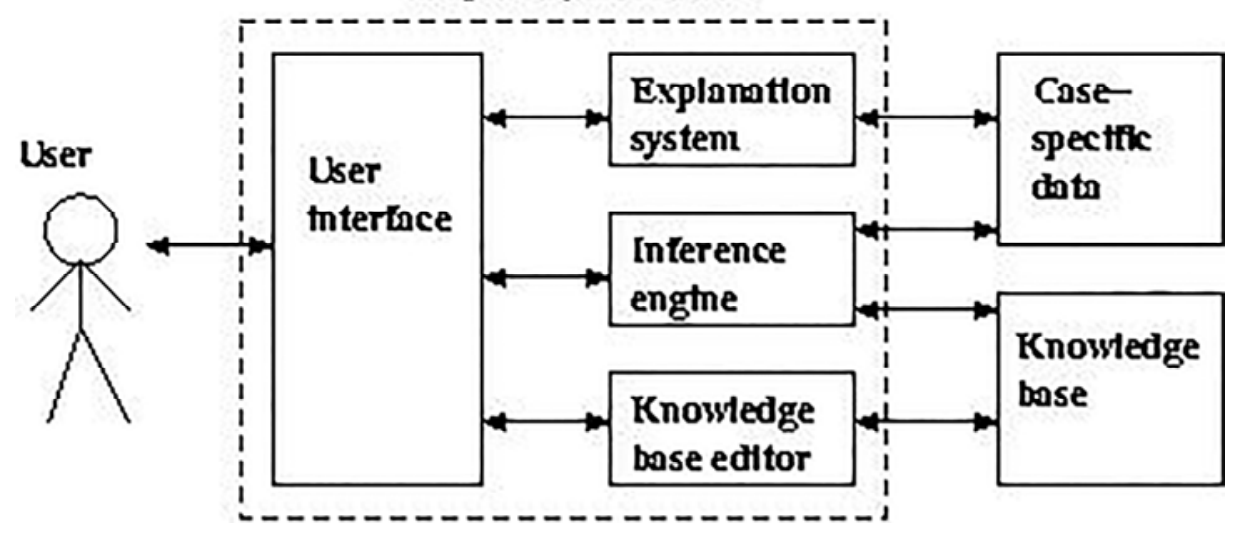

Fig. 1. Modules that make up a rule-based expert system.

As we see in the figure, the shell will provide the inference engine (and knowledge representation scheme), a user interface, an explanation system and sometimes a knowledge base editor. Given a new kind of problem to solve (say, car design), we can usually find a shell that provides the right sort of support for that problem, so all we need to do is provide the expert knowledge.

There are numerous commercial expert system shells, each one appropriate for a slightly different range of problems.

Expert systems work in industry includes both writing expert system shells and writing expert systems using shells. Using shells to write expert systems generally greatly reduces the cost and time of development (compared with writing the expert system from scratch).

Writing an expert system generally involves a great deal of time and money. To avoid costly and embarrassing failures, people have developed a set of guidelines to determine whether a problem is suitable for an expert system solution:

The need for a solution must justify the costs involved in development. There must be a realistic assessment of the costs and benefits involved.

Human expertise is not available in all situations where it is needed. If the "expert" knowledge is widely available it is unlikely that it will be worth developing an expert system. However, in areas like oil exploration and medicine there may be rare specialized knowledge which could be cheaply provided by an expert system, as and when required, without having to fly in your friendly (but very highly paid) expert.

The problem may be solved using symbolic reasoning techniques. It shouldn't require manual dexterity or physical skill.

The problem is well structured and does not require (much) common sense knowledge. Common sense knowledge is notoriously hard to capture and represent. It turns out that highly technical fields are easier to deal with, and tend to involve relatively small amounts of well formalized knowledge.

The problem cannot be easily solved using more traditional computing methods. If there's a good algorithmic solution to a problem, you don't want to use an expert system.

Cooperative and articulate experts exist. For an expert system project to be successful it is essential that the experts are willing to help, and don't feel that their job is threatened. 
Also need any management and potential users to be involved and have positive attitudes to the whole thing.

The problem is of proper size and scope. Typically you need problems that require highly specialized expertise, but would only take a human expert a short time to solve (say an hour, max).

It should be clear that only a small range of problems are appropriate for expert system technology. However, given a suitable problem, expert systems can bring enormous benefits. Systems have been developed, for example, to help analyze samples collected in oil exploration, and to help configure computer systems. Both these systems are (or were) in active use, saving large amounts of money.

\section{Case study on the application of the FUZZY concept on the Romanian metallurgical industry}

Applying the FUZZY concept in metallurgy implicitly assumes the development and implementation of ERP systems as well. A positive and relevant example of effective implementation and development of ERP systems in the Romanian metallurgy is the SC Tenaris S.A. Calarasi. The relevance of this example resides in the leading position of this company in the Romanian metallurgical industry. So, the modern organization and planning system of this production unit ensures a high level of technological and economic efficiency. In this work, we will also present a case study applying Fuzzy networks on data characteristic for SC Tenaris S.A. Calarasi.

There are two types of motivations that determine to implement ERP, which are also characteristic for SC Tenaris S.A. Călăraşi [4-6]:

\section{A. Technological motivations:}

- Replacing a non-integrated information system (multiple applications, obsolete or not, which operate independently);

- Replacing one or more obsolete systems, integrated or not;

- Improving the quality and accessibility of information;

- Integrating business processes and supporting systems;

- Acquisition of a system able to support projected business increase;

- Simplification of the integration of new businesses (acquisition of other companies) into the current technological infrastructure.

\section{B. Operational motivations}

- Optimization of business processes;

- Reduction of structural costs;

- Improving response times to customer requests;

- Simplifying complex, but ineffective business processes;

- Implementation of new business strategies;

- Massive business expansion;

- Standardization of business processes at company level.

Ergonomics represent the study of the physical and psychological aspects of work. It is primarily concerned with designing jobs and work environments that are safe and efficient. For example, such human characteristics as size, reach and flexibility must match the machines and tools that people have to use.

Escalation clause is a clause in a contract authorizing the contractor to increase the price in specified conditions of all or part or goods he has contracted to supply. Escalation clauses are common in contracts involving work over a long period in time of high inflation. 
In Figure 2 we set forth an algorithmic diagram of an Analytic and Intelligent Strategy (AIS).

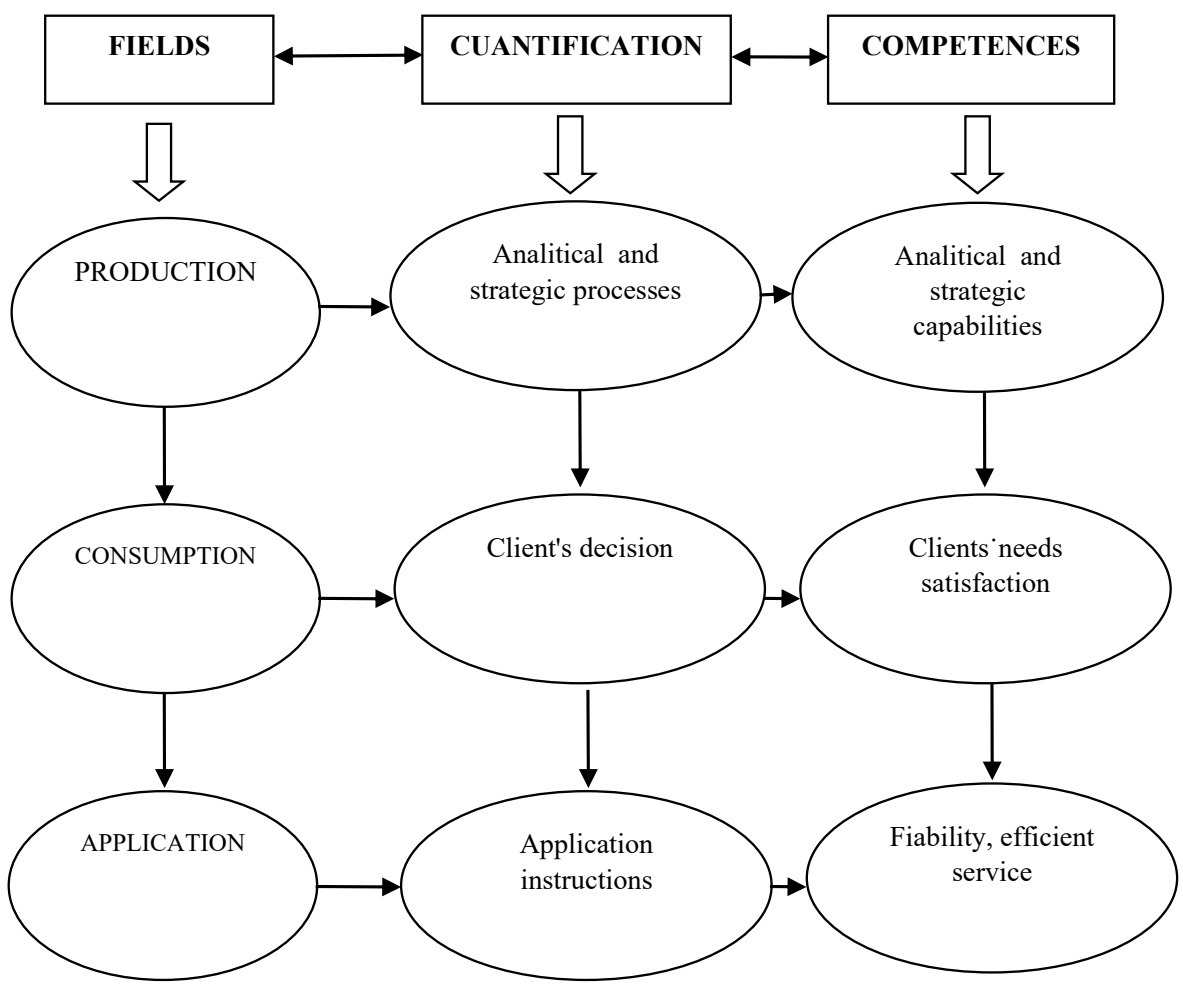

Fig. 2. Algorithmic diagram of AIS.

We have set up a case study applying Fuzzy networks based on AIS and on SAI and on ERP and ES concepts previously analyzed. Fuzzy logic is a powerful methodology for solving specific issues (including case studies), offering a multitude of applications in controlling and information processing. This powerful methodology gives us an effective way to draw precise conclusions stemming vague, ambiguous or imprecise pieces of information.

Fuzzy logic based applications can lead to any of its potential benefits, such as: performance, productivity, simplicity and lower costs (Figure 3).

The Fuzzy networks principle is to use neural networks and fuzzy set theory for modelling practical systems. The algorithm related to a Fuzzy network is implemented as an inference engine that can automatically deduce precise conclusions from certain facts (data).

Equity-linked policy is an insurance or assurance policy in which a proportion of the premiums paid are invested in equities.

The surrender value of the policy is therefore the selling price of the equities purchased. As more premiums are paid the portfolio gets larger.

Although investment returns may be considerably better on this type of policy than on a traditional endowment policy, the risk is greater, as the price equities can fall dramatically reducing the value of the policy. 
With unit-linked policies, a much wider range of investments can be achieved and the risk is correspondingly reduced.

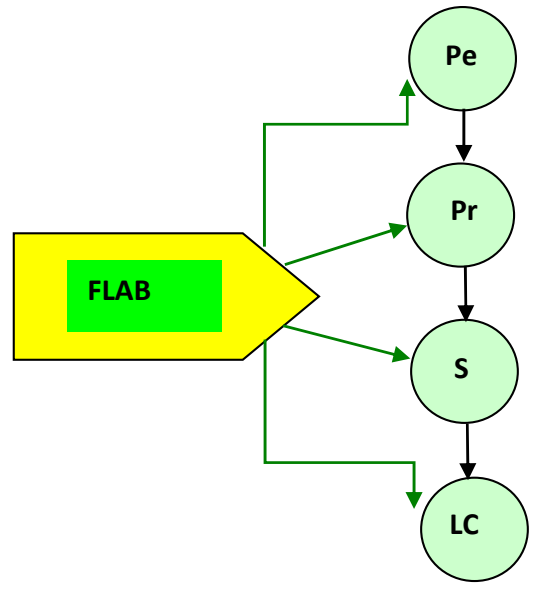

Fig. 3. Fuzzy Logic Application Benefits (FLAB).

Pe - Performance; Pr - Productivity; S - Simplicity; LC - Low Costs

Case study data rendering consumption (sales) analyze of an assortment of metallic products (high alloy, stainless and refractory steels) are set forth in Figure 4 (the variation of numerical results pertaining to Fuzzy networks specific for consumption (sales) analyze of metallic products).

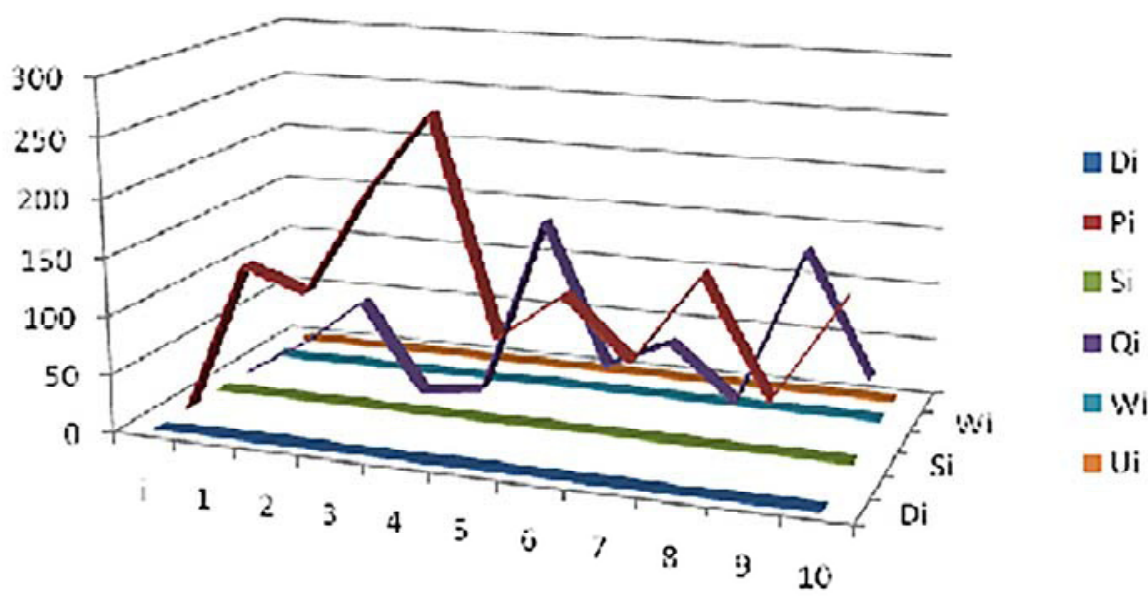

Fig. 4. Variation of numerical results pertaining to Fuzzy networks specific for consumption (sales) analyze of metallic products.

i - Analyzed type of metallic product

$\mathrm{Di}$ - Parameter for clients' subjective evaluation with respect to consumption (depreciation)

$\mathrm{Pi}$ - Price of product type

$\mathrm{Si}$ - Costs related to "i" type product (percentage) 
Qi - Factor of subjective satisfaction quantification by consumers related to consumption value

$\mathrm{Wi}$ - Consumer's preference share

Ui - Utility function for each "i" product type.

\section{Conclusions}

Applying the fuzzy concept in the metallic materials industry has as main purpose and results to increase efficiency in producing and selling these materials. An important role in achieving this purpose is also played by complementary factors such as: Expert Systems (ES), Enterprise Resource Planning (ERP), Analytics and Intelligent Strategies (SAI).

Architecture of Expert Systems has the following elements: Inference Engine (IE), Dialogue Interface (DI), Knowledge Acquiring Module (KAM), and Explanatory Module (EM).

The case study of applying the fuzzy concept in the metallic materials industry was based on two sets of preliminary conditions motivations on one hand a set of technological (motivations) and on the other hand a set of operational motivations (dealing with the execution).

Algorithmic diagram of an Analytic and Intelligent Strategy (AIS) contains the fields: production, consumption, application.

Equity accounting is the practice of showing in a company-s accounts a share of the undistributed profits of another company in which it holds a share of between $20 \%$ and $50 \%$.

The share of profit shown by the equity-holding company is usually equal to its share of the equity in the other company. Although none of the profit may actually be paid over, the company has right to this share of the undistributed profit.

Ethical dilemmas is the moral quandaries that can occur in running a business. While not confronting the law, most of these dilemmas arise as a result of conflict between what the businessperson sees as a necessary in the interests of the business and his or her personal ethical values.

\section{References}

1. N. Bharadwaj, R. Walker Naylor and F. Hofstede, IJRM, 26(3), 216-227, (2009).

2. M. Costoiu,A. Ioana, A. Semenescu, N. Constantin, B. Florea, V. Rucai, C. Dobrescu, M. Polifroni, L. Păunescu, EEMJ, 15, No. 10, 2279-2284, (2016).

3. M. Costoiu, A. Ioana, A. Semenescu, D. Marcu, IOP Conference Series-Materials Science and Engineering, 161, 012104, (2016)

4. M. Costoiu, A. Ioana, A. Semenescu, D. Marcu, IOP Conference Series-Materials Science and Engineering, 161, 012105, (2016).

5. A. Ioana, RRSI, 43, 169-179, (2013).

6. A. Ioana, A. Semenescu, Technological, JOM, 65, Issue 8, 951-957, (2013).

7. A. Ioana, V. Mirea, C. Bălescu, JECECSR, 2, 129-137, (2010). 